\title{
PEMBENTUKAN DAN PENDIDIKAN KADER KESEHATAN JIWA DALAM MENDETEKSI GANGGUAN JIWA DI WILAYAH KERJA PUSKESMAS BANDAR JAYA KABUPATEN LAHAT TAHUN 2020
}

\author{
Yeni Elviani'1), A. Gani'1), Wahyu Dwi Ari Wlbowo²) \\ ${ }^{1)}$ Program Studi DIII Keperawatan, Politeknik Kesehatan Kemenkes Palembang, Palembang, Sumatera Selatan, \\ Indonesia \\ Corresponding author: Wahyu Dwi Ari Wibowo \\ E-mail : wahyudwi74@poltekkespalembang.ac.id
}

Diterima 01 November 2021, Disetujui 05 November 2021

\begin{abstract}
ABSTRAK
Terbentuknya kader kesehatan jiwa di masyarakat merupakan angin segar bagi pelayanan kesehatan jiwa. Hal ini harus didukung oleh tingkat pengetahuan, kemampuan, dan pengalaman kader dalam menangani penderita gangguan jiwa, sehingga perlu diadakan pendidikan bagi kader kesehatan jiwa dalam penanganan gangguan jiwa dan deteksi gangguan jiwa di masyarakat. Kader kesehatan jiwa berperan sebagai penghubung antara tenaga kesehatan di fasilitas kesehatan dengan masyarakat. Metode dilakukan dengan cara berkoordinasi dengan ketua kader kesehatan dan petugas kesehatan di Puskesmas Bandar Jaya untuk membentuk kader kesehatan jiwa dan memberikan edukasi kader terkait penanganan dan pendeteksian gangguan jiwa.Tingkat pengetahuan kader tentang penanganan dan pendeteksian gangguan jiwa sebelum dibentuknya kader kesehatan jiwa dan pendidikan kesehatan pada kategori kurang $(75 \%)$ dan cukup (25\%), dan semua kader tidak dapat mendeteksi gangguan jiwa. Setelah mendapatkan penyuluhan terjadi peningkatan pengetahuan kader pada kategori baik menjadi $60 \%$, kategori baik $40 \%$, dan tidak ada kader dalam kategori tingkat pengetahuan kurang, untuk deteksi gangguan jiwa $75 \%$ kader mampu mendeteksi gangguan jiwa. Setelah terciptanya kader kesehatan jiwa dan kegiatan ini diharapkan dapat menciptakan kader kesehatan jiwa di masyarakat yang dapat meningkatkan efektivitas pencegahan, kuratif, dan pemulihan masalah kesehatan jiwa khususnya dalam penanganan dan pendeteksian gangguan jiwa di masyarakat.
\end{abstract}

Kata kunci: kader kesehatan jiwa; dekteksi gangguan jiwa; gangguan jiwa; komunitas.

\begin{abstract}
The establishment of mental health cadres in the community is good news for mental health services. It must be supported by the cadre's level of knowledge, ability, and experience in handling people with mental disorders. It is necessary to educate mental health cadres on handling mental disorders and detecting mental disorders in the community. Mental health cadres serve as a communicator between health workers in health facilities and the community. The method is used by coordinating with cadre's leader and health workers in the Bandar Jaya Public health center to educate cadres about handling and detecting mental disorders. The level of knowledge of cadres before education and training was $74 \%$ of respondents lacking knowledge, $25 \%$ of respondents had sufficient knowledge, and no one of respondents had good knowledge of handling and detecting mental disorders. The level of knowledge obtained after education was carried out, and there was an increase in knowledge where $60 \%$ of respondents obtained good knowledge scores, $40 \%$ of respondents had sufficient knowledge. There were no respondents who found that their level of knowledge was lacking. This activity is expected to create mental health cadres in the community to increase the effectiveness of preventive, curative, and recovery mental health problems, especially in handling and detecting mental disorders in the community.
\end{abstract}

Keywords: mental health cadre; mental disorder detection; mental disorders; community.

\section{PENDAHULUAN}

kondisi kesehatan yang melibatkan perubahan emosi, pemikiran atau perilaku(atau kombinasi dari semuanya (Parekh, 2018). Penyakit mental berhubungan dengan distres dan/atau masalah yang berfungsi dalam aktivitas sosial, pekerjaan atau keluarga, sedangkan menurut Menurut Keliat et al, (2013) gangguan jiwa yaitu suatu perubahan yang menyebabkan adanya gangguan pada fungsi jiwa, yang menimbulkan penderitaan pada individu atau hambatan dalam melaksanakan peran social (Keliat, B. A., Akemat, Daulima, N. H., \& Nurhaeni, 2013). 
Pada tahun 2016, International Health Metrics and Evaluation (IHME) mencatat bahwa ada lebih dari 1,1 miliar penduduk di dunia mengalami penyakit gangguan mental (databoks, 2016), sedangkan di Indonesia berdarakan Riset esehatan Dasar (RISKESDAS) pada tahun 2018 mencatat terdapat 0,67 persen dari total rumah tangga yang anggotanya menderita skizofrenia atau psikosis. Namun sebanyak 51,1 persen individu yang mengalaminya tidak rutin meminum obat. Salah satu alasan tidak rutin meminum obat adalah karena mendapatkan tindakan diskriminatif, perisakan, dan stigma negatif (RISKESDAS, 2018).

Gangguan jiwa kerap kali diasumsikan karena adanya guna-guna, kutukan, gangguan roh atau kurang iman. Permasalahan lain karena kurangnya fasilitas dan tenaga kesehatan jiwa. Pengetahuan yang terbatas mengenai penyebab, gejala dan pengobatan penyakit jiwa akan membuat individu merasa bahwa penyakit jiwa berasal dari roh-roh jahat, kutukan, hukuman atau bagian dari garis keturunan, padahal penyakit jiwa tersebut berasal dari diri individu itusendiri (Wu \& Chen, 2016).

Akar permasalahan pada kesehatan mental berasal dari tiga inti pokok. Pertama adalah pemahaman masyarakat yang kurang mengenai gangguan jiwa, kedua adalah stigma mengenai gangguan jiwa yang berkembang di masyarakat, dan ketiga adalah tidak meratanya pelayanan kesehatan mental. Dengan demikian penanganan gangguan jiwa bukan hanya menjadi tanggungjawab tenaga kesehatan tetapi juga tenaga non kesehatan termasuk didalamnya masyarakat (Purnama et al., 2016)

$70 \%$ penderita gangguan jiwa hidup bersama dan menggantungkan hidupnya pada keluarga mereka. Kader sebagai bagian masyarakat dan keberadaanya di tengah-tengah masyarakat diharapkan dapat berperan aktif dalam turut serta mengentaskan masalah gangguan jiwa (Farkhah \& Suryani, 2017). Oleh karena itu, kader kesehatan dituntut untuk mampu memahami bagaimana kondisi gangguan jiwa di masyarakat. Pemahaman tersebut dapat diawali oleh pengetahuan kader yang baik mengenai gangguan jiwa dan cara deteksi awal ganggun jiwa. Menurut Sahiran, (2018) "Kader sebagai bagian dari masyarakat dianggap lebih dekat, berdampingan, dan mampu menjangkau seluruh lapisan masyarakat (Sunarti, 2019)

Menurut penelitian yang dilakukan purnomo, (2018) pada 33 kader kesehatan didaptkan hasil bahwa terdapat pengaruh yang signifikan terhadap peningkatan pengetahuan, sikap dan kecenderungan perilaku tentang perawatan pasien gangguan jiwa pada kader kesehatan jiwa di Kabupaten Sukoharjo setelah diberikan pendidikan keseahatan (PURNOMO, 2018), akan tetapi berdasarkan studi pendahuluan yang dilakukkan pada 20 anggota kader puskesmas Puskesmas Bandar Jaya, ternyata selama ini belum mendapatkan pendidikan kesehatan penanganan pasien gangguan jiwa dan deteksi awal gangguan kesehatan jiwa di masyarakat.

Berdasarkan permasalahan di atas perlu adanya upaya pembentukan kader kesehatan jiwa dan pendidikan Pendidikan Kader Kesehatan Jiwa yang nantinya akan menjadi penghubung antara petugas kesehatan dan masyarakat dalam mendeteksi gangguan jiwa di wilayah kerja Puskesmas Bandar Jaya Kabupaten Lahat Tahun 2020.

\section{METODE}

Kegiatan pengabdian kepada masyarakat dilaksanakan di Puskemas Bandar Jaya Kecamatan Lahat Kabupaten Lahat pada tanggal 27-30 September dan 7 Oktober 2020. Sasaran kegiatan PKM adalah 20 kader kesehatan. Kegiatan PKM ini dilaksanakan oleh 2 dosen dan dibantu oleh 5 mahasiswa DIII Keperawatan.

Pada kegiatan ini mahasiswa bertugas membantu menyiapkan alat dan bahan yang digunakan untuk pelatihan kader kesehatan jiwa, pengisian daftar hadir dan pemberian konsumsi kepada peserta PKM. Kegiatan ini dilakukan dengan cara penyuluhan kepada peserta PKM.

Tahapan pelaksanaan kegiatan difokuskan pada 3 kegiatan yaitu:

1. Tahap pertama merupakan tahap perencanaan kegiatan yang akan dilakukan. Proses perencanaan meliputi survey lapangan dan rapat koordinasi dengan mitra dan petugas kesehatan meliputi identifikasi kebutuhan masalah, karakteristik mitra, tempat pelatihan, kesepakatan tempat dan waktu pelatihan yang disusun bersama dengan perangkat desa, tokoh masyarakat dan kader yang ada di wilayah kerja Puskesmas Bandar Jaya.

2. Tahap kedua merupakan tahap pelaksanaan kegiatan pengabdian masyarakat yang dilakukan oleh tim yang terlibat dalam IbM penyuluhan dan pelatihan yaitu dosen, mahasiswa, dan kader kesehatan untuk menjadi kader kesehatan jiwa.

3. Tahap ke tiga dilakukan monitoring dan evaluasi kegiatan. Proses ini dilakukan sendiri oleh Tim Pengabdian Masyarakat kepada peserta pelatihan. Bentuk monitoring yang dilakukan adalah pertanyaan secara langsung guna mengetahui tingkat capaian kemampuan

\section{HASIL DAN PEMBAHASAN}

Hasil kegiatan pengabdian pada masyarakat menunjukan bahwa beberapa orang telah terhimpun dalam suatu kelompok yang disebut Kader Kesehatan Jiwa (KKJ). 
Keanggotaan KKJ ini sebagian besar didominasi oleh kader kesehatan Posyandu karena mereka yang aktif mengikuti rangkaian kegiatan mulai sosialisasi sampai penyuluhan. Proses awal pembentukan KKJ adalah sosialisasi selanjutnya pembentukan KKJ.

Tabel 1. Karakteristik Kader Jiwa di Puskesmas Bandar Jaya

\begin{tabular}{lcc}
\hline Pengetahuan & Frekuensi(n) & Presentase(\%) \\
\hline Jenis Kelamin & & 100 \\
\hline Perempuan & 20 & \\
\hline Umur & & 45 \\
\hline $20-\leq 35$ Tahun & 9 & 55 \\
\hline$\geq 35$ & 11 & \\
\hline Pendidikan & & 30 \\
\hline $\begin{array}{l}\text { Rendah (SD- } \\
\text { SMP) }\end{array}$ & 6 & 70 \\
\hline Tinggi ( $\geq$ SLTA) & 14 & \\
\hline Pekerjaan & & 25 \\
\hline Bekerja & 5 & 75 \\
\hline Tidak bekerja & 15 &
\end{tabular}

Tabel 1 menunjukkan jenis kelamin sebagian besar kader jiwa adalah perempuan sebanyak 20 orang (100\%), berdasarkan usia terbanyak dengan usia $\geq 35$ tahun sejumlah 11 orang $(55 \%)$, dan tingkat pendidikan sejumlah 14 orang $(70 \%)$ berpendidikan Tinggi ( $\geq$ SLTA). Berdasarkan usia terbanyak pekerjaan sejumlah 15 orang tidak bekerja (55\%)

Tabel 2. Distribusi Nilai Pengetahuan Responden Sebelum Diberikan Pendidikan Kesehatan

\begin{tabular}{c|c|c} 
Pengetahuan & Frekuensi (n) & Presentase (\%) \\
\hline Kurang & 0 & 0 \\
\hline Cukup & 8 & 20 \\
\hline Baik & 12 & 60 \\
\hline
\end{tabular}

Tabel 2 menunjukan bahwa tingkat pengetahuan kader tentang penanganan dan pendeteksian gangguan jiwa sebelum diberikan pendidikan kesehatan pendidikan kesehatan pada kategori kurang sebanyak 15 orang $(75 \%)$ dan pada katagori cukup 5 orang (25\%), Pengetahuan adalah hasil penginderaan terhadap suatu objek, penginderaan manusia terdiri dari indera pengelihatan, pendengaran, penciuman, rasa dan raba, dimana mayoritas pengetahuan didapatkan dengan menggunakan mata dan telinga untuk mempengaruhi pengetahuan yang diterima (Notoatmodjo, 2011) Media disusun dengan prinsip setiap pengetahuan diterima oleh panca indra. Kemampuan panca indera yang digunakan untuk menerima sesuatu semakin banyak maka semakin banyak dan jelas pengetahuan yang didapatkan. Media audio visual memberikan informasi melalui suara dan gambar sehingga informasi yang didapatkan oleh penerima dirasakan melalui indera mata dan telinga (Notoatmodjo, 2011). Belum ada penelitian atau pengabdian masyarakat yang meneliti tentang pengetahuan kader jiwa sebelum di lakukan pelatihan posyandu jiwa, namun ada beberapa penelitian serupa seperti penelitian yang dilakukan oleh Saleh dan Kunoli dengan judul pengaruh penyuluhan dan pelatihan melalui media leaflet terhadap pengetahuan kader phbs di kecamatan ratolindo kabupaten tojouna-una menunjukkan bawa $50 \%$ responden berpengetahuan rendah (Saleh A, n.d.).

Pengetahuan yang rendah atau kurang dapat terjadi karena kurangnya terpaparnya informasi tentang permasalahan kesehatan jiwa, selain itu bisa juga dipengaruhi oleh pendidikan dimana $70 \%$ kader berpendidikan SMA yang memang selama pendidikan disekolah belum mendapatkan tetang materi bagaimana cara mengenal dan menangani masalah kesehatan jiwa.

Tabel 3. Distribusi Nilai Pengetahuan Responden Setelah Diberikan Pendidikan Kesehatan

\begin{tabular}{c|c|c} 
Pengetahuan & Frekuensi (n) & Presentase (\%) \\
\hline Kurang & 15 & 75 \\
\hline Cukup & 5 & 25 \\
\hline Baik & 0 & 0 \\
\hline
\end{tabular}

Table 3 menunjukan distribusi nilai pengetahuan responden setelah diberikan pelatihan kader menunjukkan terjadi peningkatan dari pengetahuan kader jiwa dimana sejumlah $60 \%$ berpengetahuan baik. terjadinya peningkatan tersebut diakatkan karena telah mendapatkan paparan nformasi melalui pelatihan kader.

Kader memiliki peran promosi dalam layanan kesehatan. Peran promosi kesehatan kader merupakan penghubung antara masyarakat di banjaratau RT/RW atau komunitas dengan petugas kesehatan khususnya puskesmas. Kegiatan kader kesehatan diharapkan meningkatkan efektivitas preventif, kuratif dan recovery masalah kesehatan. Kader kesehatan memiliki peran memberikan (Jayanti \& DKK, 2019)

motivasi dalam minum obat dengan teratur kepada pasien, menjelaskan kepada keluarga dalam memperhatikan dan mengawasi pengobatan pasien, memberikan dukungan kepada keluarga dan pasien dalam mengikuti kegiatan kelompok seperti aktivitas di lingkungan sekitar dan penyuluhan kesehatan serta pasien dihimbau untuk memeriksakan secara teratur di puskesmas (Model et al., 2013). Berdasarkan hal tersebut maka kader perlu memiliki pengetahuan yang baik.

menyatakan informasi sangat mempengaruhi pengetahuan seseorang sehingga terjadi perubahan pengetahuan dari dominan pengetahuan kurang saat pre test berubah menjadi dominan memiliki pengetahuan baik setelah diberikan pelatihan. Sumber daya 
manusia yang berkualitas dapat meningkatkan kualitas hidup dan prognosis penyakit pada ODGJ (Jayanti \& DKK, 2019).

Tabel 4. Distribusi Kemampuan Kader Mendeteksi Gangguan Jiwa

\begin{tabular}{cccc}
\hline Kemampuan & Katagori & Frekuensi & Persentase \\
\hline $\begin{array}{c}\text { Sebelum } \\
\text { Pelatihan }\end{array}$ & $\begin{array}{c}\text { Mampu } \\
\text { Mampu }\end{array}$ & 0 & 0 \\
\hline $\begin{array}{c}\text { Setelah } \\
\text { Pelatihan }\end{array}$ & Mampu & 15 & $100 \%$ \\
\cline { 2 - 4 } & $\begin{array}{c}\text { Belum } \\
\text { Mampu }\end{array}$ & 5 & $75 \%$ \\
\hline
\end{tabular}

Tabel 4 menunjukan ada peningkatan $75 \%$ dari sebelum dan sesudah diberikan pelatihan para kader untuk melakukan deteksi deteksi dini atau skrining keluarga gangguan gangguan jiwa $75 \%$ kader mampu mendeteksi gangguan jiwa. Pengukuran kemampuan kader melakukan skrining dinilai dari kemampuan melakukan deteksi keluarga, memilah (keluarga gangguan, resiko, atau sehat), lalu melakukan pencatatan pada buku kerja. Pelatihan yang diberikan bagi kader lebih difokuskan pada bagaimana mereka agar mampu melakukan deteksi keluarga gangguan di masyarakat. Peningkatan kemampuan kader terlihat dari hasil buku kerja yang diisi oleh kader pada saat melakukan deteksi di masyarakat. Kader pada awalnya belum mampu melakukan deteksi keluarga gangguan. Hasil ini dapat terlihat pada tabel 4 dimana seluruh kader belum mampu melakukan deteksi keluarga gangguan. Oleh karena itu, tim memberikan kembali materi mengenai kesehatan jiwa kepada para kader dengan tujuan penyegaran. Materi selanjutnya difokuskan pada kegiatan melatih para kader agar mampu medeteksi keluarga gangguan. Beberapa kader tampak menunjukan kemampuannya membedakan antara seseorang yang mengalami gangguan jiwa dan tidak mengalami gangguan jiwa. Pelatihan yang dilakukan berhubungan dengan perilaku penyampaian informasi. Tanggung jawab yang diemban para kader menjadi bertambah, selain melakukan berbagai kegiatan Posyandu juga mendeteksi keluarga gangguan serta menggerakkan mereka agar aktif mengikuti penyuluhan kesehatan jiwa (Kosasih et al., 2018). Dengan demikian pembentukan kader ini sangat bermanfaat sebagai langkah awal dalam mengatasi permasalahan kesehatan jiwa di Puskesmas Bandar Jaya.
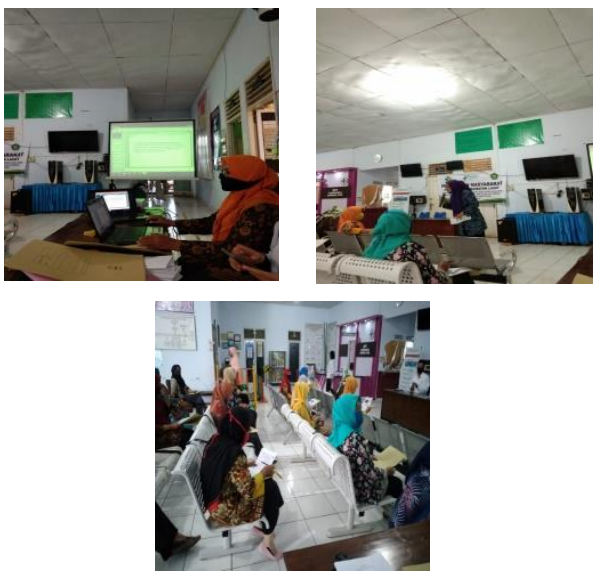

Gambar 1. Proses Pemberian Materi

\section{SIMPULAN}

Pengabdian masyarakat dapat dilaksanakan di Puskesmas Bandar Jaya Kecamatan Lahat, kader kesehatan yang dibentuk menjadi kader kesehatan Jiwa sangat antusis dan semangat dalam tanya jawab mengenai materi pelatihan. Diharapkan setelah mengikuti kegiatan pengabdian masyarakat berupa pembentukan dan pelatihan kader kesehatan jiwa dalam mendeteksi gangguan jiwa, kader dapat melakukan penanganan ganggun jiwa dan deteksi gangguan jiwa di masyarakat, sehingga penanggulangan masalah gangguan jiwa dapat segera diatasi bersama petugas kesehatan jiwa di Puskesmas Bandar Jaya.

\section{UCAPAN TERIMA KASIH}

Penulis mengucapkan terima kasih kepada Poltekkes Kemenkes Palembang yang telah memberi dukungan financial terhadap pengabdian ini. Tak lupa kami mengucapkan terima kasih kepada Kepala Puskesmas Bandar Jaya dan staf yang telah memfasilitasi kegiatan ini sehingga dapat berjalan dengan baik dan lancar.

\section{DAFTAR RUJUKAN}

Databoks. (2016). Databooks, 2016.pdf. https://databoks.katadata.co.id/datapublish /2018/06/09/negara-negara-denganpenderita-gangguan-mental-terbesar

Farkhah, L., \& Suryani, S. (2017). Faktor Caregiver dan Kekambuhan Klien Skizofrenia. Jurnal Keperawatan Padjadjaran, 5(1), 37-46. https://doi.org/10.24198/jkp.v5n1.5

Jayanti, D. M. A. D., \& DKK. (2019). Peningkatan Kesehatan Jiwa Melalui Peran Kader Kesehatan Jiwa. Jurnal Difusi, 2(1), 33-40.

Keliat, B. A., Akemat, Daulima, N. H., \& Nurhaeni, H. (2013). Keperawatan Kesehatan Jiwa Komunitas : CMHN (Basic Course). EGC.

Kosasih, C. E., Isabella, C., Purba, H., \& Sriati, A. (2018). Upaya Peningkatan Gizi Balita 
Melalui Pelatihan Kader Kesehatan Pendahuluan Keadaan gizi masyarakat Indonesia pada saat ini masih belum menggembirakan. Berbagai masalah gizi seperti: gizi kurang dan gizi buruk, kekurangan vitaminA, anemia gizi besi ,. Mkk, 1(1), 90-100. file:///D:/KTI2020/upaya-kader-gizi-jurnal.pdf

Model, P., Green, P. L., Rw, D. I., Tanah, D. A. N., Pramujiwati, D., Keliat, B. A., \& Wardani, Y. (2013). Pemberdayaan Keluarga dan Kader Kesehatan Jiwa Dalan Penanganan Pasien Harga Diri Rendah Kronik Dengan Pendekatan Model Precede L.Green Di RW 06, 07 dan 10 Tanah Baru Bogor Utara. Jurnal Keperawatan Jiwa, 1(2), 170-177.

Notoatmodjo, S. (2011). (2011). IImu Seni Kesehatan masyarakat. Rineka Cipta.

Parekh. (2018). mental ilnes.pdf. The American Psychiatric Association (APA). https://www.psychiatry.org/patientsfamilies/what-is-mental-illness

Purnama, G., Yani, D. I., \& Sutini, T. (2016). Gambaran stigma masyarakat terhadap klien. Jurnal Pendidikan Keperawatan Indonesia, 2(1), 29-37. https://ejournal.upi.edu/index.php/JPKI/arti cle/view/2850

PURNOMO, H. J. (2018). PROMOSI KESEHATAN UNTUK MENGETAHUI PERUBAHAN PENGETAHUAN, SIKAP, DAN KECENDERUNGAN BERPERILAKU PADA KADER YANG ADA ANGGOTA MASYARAKATNYA YANG MENGALAMI GANGGUAN JIWA DI KABUPATEN SUKOHARJ [UNIVERSITAS MUHAMMADIYAH SURAKARTA] http://eprints.ums.ac.id/66364/1/NASKAH PUBLIKASI.pdf

RISKESDAS. Laporan_Nasional_RKD2018_FINAL.pdf. In Riskesdas (p. 198). Kementerian Kesehatan Republik Indonesia. http://labdata.litbang.kemkes.go.id/images/ download/laporan/RKD/2018/Laporan_Nas ional_RKD2018_FINAL.pdf

Saleh A, K. F. (n.d.). Pengaruh penyuluhan dan pelatihan melalui media leaflet terhadap pengetahuan kader PHBS di Kecamatan Ratolindo kabupaten Tojo Una-una. Urnal Kesehatan Masyarakat. 2018, 159-164.

Sunarti. (2019). peran, kader, posyandu PERAN KADER KESEHATAN PELAYANAN POSYANDU UPTD PUSKESMAS KECAMATAN SANANWETAN KOTA BLITAR. Jurnal Keperawatan Malang, 3(2), 94-100. https://doi.org/10.36916/jkm.v3i2.63

Wu, H. C., \& Chen, F. P. (2016). Sociocultural factors associated with caregiverpsychiatrist relationship in Taiwan. Psychiatry Investigation, 13(3), 288-296. 